\title{
Novel insight into Potential Leishmanicidal Activities of Transdermal Patches of Nigella Sativa. Formulation Development, Physical Characterizations and In vitro In vivo Assays
}

\section{Barkat Ali Khan}

Gomal University

Yasmin Asmat

Gomal University

Tariq Hayat Khan

Lady Reading Hospital

Mughal Qayum

Kohat University of Science and Technology

Sultan Muhammad Alshahrani

King Khalid University

Ali Alqahtani

King Khalid University

Muhammad Khalid Khan ( $\square$ khalid.gomalian@gmail.com )

Gomal University

\section{Research Article}

Keywords: Leishmaniasis, Nigella sativa, Transdermal Patch, Leishmanicidal action

Posted Date: April 2nd, 2021

DOI: https://doi.org/10.21203/rs.3.rs-352742/v1

License: (c) (i) This work is licensed under a Creative Commons Attribution 4.0 International License.

Read Full License

Version of Record: A version of this preprint was published at ASSAY and Drug Development Technologies on September 1st, 2021. See the published version at https://doi.org/10.1089/adt.2021.035. 


\section{Abstract}

Cutaneous Leishmaniasis (CL) is the most common type of Leishmaniasis which annually affects 1.5 million people worldwide. About $90 \%$ of cases are reported from countries such as Iran, Afghanistan, Pakistan, Iraq, and Saudi Arabia. The purpose of the present study was to fabricate transdermal patches of Nigella sativa (NS), characterize and to check its in vitro in vivo anti-Lieshmanial activity. Hydroalcohlic extract was analyzed for preliminary phytochemicals. Five formulations of transdermal patches (NS1, NS2, NS3, NS4 and NS5) were prepared by solvent evaporation method. The optimized formulation NS5 was characterized for FTIR, smoothness, brittleness, clarity, thickness, folding endurance, uniformity of weight, percent moisture content, in-vitro drug release, release kinetics, ex vivo drug permeation and invitro anti-Lieshmanial activity. In vivo anti-Lieshmanial activity was assessed in 30 patients $(n=30)$ suffering from $\mathrm{CL}$. The FTIR studies showed no incompatibility among the active extract and polymers. In vitro anti-Lieshmanial assay was $194.6 \pm 1.88 \%$ as compared to standard drug $(p>0.05)$ and in vivo antiLieshmanial activity was $75 \%$. The drug release after 24 hours was $87.0 \pm 0.94 \%$ in NS5 which showed non-Fickian diffusion mechanism while drug permeation across rabbit skin after 24 hours was up to 80.0 $\pm 0.91 \%$. The results concluded that problems related to the medications parenterally used for Lieshmanial treatment can be managed by applying extract of Nigella sativa seeds in the form of transdermal patch.

\section{Introduction}

Leishmaniasis is a common disease throughout tropical, sub-tropical and temperate regions of the America, Europe, Asia, and Africa, with an estimated 12 million people infected and more than 350 million people at risk. ${ }^{1}$ It is vector-borne disease caused by a protozoan endo-parasite species belonging to the genus Leishmania that live in the blood and tissues of the host, its mode is through the bite of Phlebotomine sandflies. ${ }^{2}$

Cutaneous Leishmaniasis (also known as oriental sore, tropical sore, chiclero ulcer) is the most common form of Leishmaniasis affecting humans. There are about twenty species of Leishmania that may cause cutaneous Leishmaniasis. ${ }^{3}$ It is a public health burden in Pakistan. The cases of CL have surged since the end of 2018 in the North West province Khyber Pakhtunkhwa (KPK). According to the health authorities about 28000 cases of CL have been reported since Nov, 2018. These cases were mostly from the newly merged districts of FATA which have borders with Afghanistan. A recent upsurge in the province's southernmost districts, particularly in South Waziristan, has driven people to the neighboring district of Bannu or even to the provincial capital, Peshawar, for treatment. ${ }^{4}$

Not a single ideal and best treatment or vaccination is available for the different clinical forms of Leishmaniasis. A number of drugs available for the treatment of Leishmaniasis include Pentavalent antimony, Paramomycin, Liposomal amphotericin B, Funconazole and the under-trial drug such as Miltefosine but all these drugs have severe nephrotoxicity due to which its long term use is risky. 5,6 
For $\mathrm{CL}$ there is a need of topical dosage form which can be applied on the skin lesions to avoid the systemic side effects of usual drugs. A new technology developed for release of drug at a controlled rate into systemic circulation through skin is very important for $C L$ to avoid the systemic side effects of usual drugs, such innovation includes transdermal patches which can be used for achieving efficient systemic effect by passing hepatic first pass metabolism and increasing the fraction absorbed. The transdermal patches provide continuous drug release through intact skin into the systemic blood stream during a prolong time at a preset rate. This dosage form came into pharmaceutical companies since $1990 .^{7,8}$ The examples of marketed transdermal patches in pharmaceuticals are cardiac medicines i.e., nitroglycerine, estrogen patches i.e., hormones, thermal and cold patches, nutrient patches, skin care patches are non-

medicated patches. ${ }^{9}$ This system provides many clinical advantages as compared to oral and parenteral system. In short transdermal patches are more safe, easy to apply, cheap, painless, and hence leads to positive patient compliance but only some drugs show well delivery across the skin so use of transdermal patches are limited in pharmaceuticals. ${ }^{10,11}$ To avoid all the negative effects of anti-leishmanial drug therapy, there is need to evaluate and use herbal extract of medicinal plants in transdermal patches which will be a very good solution of the problem. ${ }^{12}$

Nigella sativa is an annual flowering plant. The black colored seeds are flattened, oblong and angular, funnel shaped, with the length of $0.2 \mathrm{~cm}$ and $0.1 \mathrm{~cm}$ wide Nigella sativa $L$, which belongs to the Ranunculaceae family. ${ }^{13}$ These are also used as a carminative and diuretic by oriental people. ${ }^{14}$ The seeds are sold in the markets to be used as a condiment and native medicine. Its main chemical constituents are Thymoquinone (TQ), dithymoquinone, fixed oil (32-40\%), saponin (Mohammed \& Arias, 2016). The pharmacological activity of Nigella sativa is because of quinine constituent, of which TQ is the most part bottomless (Chehl et al., 2009), TQ possess anticonvulsant activity antioxidant, antiparasitic, anti-inflammatory, anti-cancer, antibacterial and antifungal activity. ${ }^{15}$

Based on the above justification, the present study was designed with the aim to formulate and characterize transdermal patches of Nigella sativa extract for possible anti Lieshmanial activity in vitro and in vivo.

\section{Materials And Methods}

Methanol, HPMC, Ethyl Cellulose, PVP, PVA (polymers), Propylene glycol, Tween-80, DMSO were purchased from Sigma Aldrich, Germany. Nigella sativa seeds Extract were purchased from local market of D. I. Khan, Pakistan. Benedict's reagent \& Wagner's reagent (lodine Reagent), Chloroform and Distilled Water were obtained from Research Lab, Faculty of Pharmacy, Gomal University, and D.I.Khan, Pakistan. Ether, ethanol, HCL, Sulphuric Acid, Ammonia, Ferric Chloride, Aluminium Chloride, NNN growth medium, fetal bovine calf serum, Gallic acid \& Folin and Ciocalteu's reagent, Silica were purchased from Hajwari Chemicals, Lahore, Pakistan.

\section{Methods}




\section{Extract Preparation}

Seeds of Nigella sativa were collected from the local market of D.I.Khan KPK Pakistan and relevant permits/permissions/licences were obtained. These were identified by Dr. Mushtaq Ahmad from "Department of Plant Sciences" of Quid I Azam University, Islamabad Pakistan. These seeds were shade dried, crushed in electric grinder and then the seeds powder was macerated in $50 \%$ methanol and distilled water for 5 days with occasional stirring after every $12 \mathrm{~h} .{ }^{12}$ The macerated seeds granules were filtered through a Muslin cloth for coarse filtration and then filtered through a Whatman \# 01 filter paper for clear extract, followed by evaporation at $40^{\circ} \mathrm{C}$ in rotary evaporator (Rotavapor ${ }^{\circledR}, \mathrm{R}-215$, Germany). The extract obtained was collected in glass jars and stored in freezer at $0^{\circ} \mathrm{C}$.

\section{Phytochemical Screening}

Phytochemical screening was performed using standard procedure for alkaloids, saponins, flavonoids, terpenoides (Salkowski test), tannins and reducing sugars. ${ }^{15-17}$

\section{HPLC Analysis}

HPLC method was developed for the quantification of extract. Briefly, C18 reversed-phase analytical column ( $25 \times 4.6 \mathrm{~mm}, 4.6 \mathrm{~mm}$ particle size) was used. $500 \mu \mathrm{l}$ of the extract was diluted with mobile phase to get final concentration of $10 \mu \mathrm{l} / \mathrm{ml}$. HPLC conditions of analysis were optimized by varying the mobile phase (Water: Methanol: 2-propanol, 50:45:5\% v/v; filtered through a $0.45 \mathrm{~mm}$ Millipore filter and deaerated before use), flow rate ( $1 \mathrm{ml} / \mathrm{mint})$, column temperature $25^{\circ} \mathrm{C}$ and wave length $(245 \mathrm{~nm}-270 \mathrm{~nm})$, Retention time was 2 to 4 mints, phosphate buffer solution used with $\mathrm{pH} 7.4 .{ }^{18}$

\section{Preparation of Transdermal Patches}

The transdermal patches were prepared by matrix method. Backing membrane was prepared by using $5 \mathrm{~g}$ of PVA $(w / v)$ in a beaker and made quantity sufficient to $100 \mathrm{ml}$ with distilled water as solvent. This beaker was kept on hot plate magnetic stirrer at $80^{\circ} \mathrm{C}$ until a clear solution is formed. This mixture was then cooled, sonicated for two minutes in a sonicator to remove any air bubbles entrapped. The mixture $(15 \mathrm{ml})$ was poured into each petri dish having a diameter of $70 \mathrm{~cm}^{2}$, dried in oven at $40^{\circ} \mathrm{C}$ and stored by raping in aluminium foil for further use. ${ }^{19}$ The transdermal patches of crude drug extract of Nigella sativa seeds were prepared by using solvent casting method using chloroform as solvent. Different ratios of polymers were evaluated in w/w (Table I). First HPMC was taken and mixed with required quantities of PG, PEG 400, Tween 80, DMSO, crude drug extract and chloroform (Q.S). The beaker was kept on magnetic stirrer for 90 min and measured quantity of ethyl cellulose (EC) and PVP were added and beaker was again kept on stirring. ${ }^{20}$ This stirred and sonicated solution was poured into the petri dishes having already dried backing membrane and placed at room temperature for drying for 24 hours. Patches were cut into a diameter of $2 \mathrm{~cm}^{2}$ of each patch with help of a sharp blade cutter.

Table I. Composition of Nigella sativa Transdermal patch 


\begin{tabular}{|c|c|c|c|c|c|c|}
\hline \multirow[b]{2}{*}{ Formulation } & \multicolumn{6}{|c|}{ Ingredients (w/w), Chloroform (QS to $100 \mathrm{mg}$ ) } \\
\hline & $\begin{array}{l}\text { EC : HPMC : } \\
\text { PVP } \\
(\mathrm{mg})\end{array}$ & $\begin{array}{l}\text { PG } \\
\% \\
(\mathrm{mg})\end{array}$ & $\begin{array}{l}\text { Tween- } \\
80 \\
(\mathrm{mg})\end{array}$ & $\begin{array}{l}\text { DMSO } \\
(\mathrm{mg})\end{array}$ & $\begin{array}{l}\text { PEG } \\
(\mathrm{mg})\end{array}$ & $\begin{array}{l}\text { Nigella sativa seed extract } \\
(\mathrm{mg}) .\end{array}$ \\
\hline NS 1 & $2.1: 1.7: 1.2$ & $25 \%$ & $8 \%$ & $8 \%$ & $5 \%$ & $25 \%$ \\
\hline NS 2 & $3.0: 0.9: 1.1$ & $25 \%$ & $8 \%$ & $8 \%$ & $5 \%$ & $25 \%$ \\
\hline NS 3 & $2.0: 1.8: 1.2$ & $25 \%$ & $8 \%$ & $8 \%$ & $5 \%$ & $25 \%$ \\
\hline NS 4 & $2.5: 1.5: 0.5$ & $25 \%$ & $8 \%$ & $8 \%$ & $5 \%$ & $25 \%$ \\
\hline NS 5 & $1.5: 2.0: 2.0$ & $25 \%$ & $8 \%$ & $8 \%$ & $5 \%$ & $25 \%$ \\
\hline
\end{tabular}

\section{Physicochemical Evaluation of Transdermal Patches Smoothness, Brittleness and Clarity}

The prepared patches were checked for smoothness and roughness by fingers.

\section{Thickness of the Patch}

The prepared drug-loaded patches were selected from all the five formulations and three patches were selected from each formulation and were measured at three different points by using a digital screw gauge. The test was triplicated and results averaged with \pm SD. ${ }^{20}$

\section{Folding Endurance}

Three patches were selected from each batch and folded repeatedly at the same place till it breaks/cracks. This gave the folding value of a patch. The test was triplicated and the results were averaged with \pm SD.

\section{Uniformity of Weight}

The prepared drug-loaded patches were weighed using a digital weighing balance. The test was performed to check the uniformity of weight and to check the batch- to- batch variation. The test was triplicated and the results were averaged with \pm SD.

\section{Percent Moisture Content}

The prepared films were selected from each batch and marked, then weighed individually and kept in a desiccator containing activated silica at room temperature for 24 hours. The films were weighed individually until it showed a constant weight. The percentage of moisture content was calculated as a difference between initial and final weight with respect to final weight. The test was triplicated and the results averaged with \pm SD. 
Moisture Content (\%) = Initial weight of patch - Final weight of patch $x 100$ (Eq. 1)

Final weight of patch

\section{Fourier Transform-infrared Spectroscopy}

FTIR spectroscopy was used to detect the vibration characteristics of functional groups in a sample and to investigate and predict physiochemical interaction between different formulation components and therefore it can be applied to the selection of chemically compatible, stable, and therapeutically acceptable ingredients. $10 \mu \mathrm{l}$ of methanolic extract of Nigella sativa seeds, transdermal patch of extract and powder of seed were taken for FTIR analysis. Nigella sativa oil with a concentration of $1 \mathrm{mg} / \mathrm{ml}$ (methanol as solvent) was taken as standard and both were placed on a diamond window of the spectrophotometer under standard room temperature. A 32 scans with a resolution of $4 \mathrm{~cm}^{-1}$ was adopted. The available spectrum region was 4000 to $400 \mathrm{~cm}^{-1} .21$

\section{Drug Release Study}

Cumulative drug release profiles from matrix patch were examined using the Franz diffusion cell. The receptor compartment was filled with air bubble-free phosphate buffer $\mathrm{pH} 5.5$ in simulation of skin $\mathrm{pH}$ using Tuffryn ${ }^{\circledR}$ membrane as barrier. The temperature of the receptor phase was maintained at $32 \pm 2^{\circ} \mathrm{C}$. The buffer solution was magnetically stirred throughout the study. Two $\mathrm{ml}$ aliquot was withdrawn at specific time intervals for $24 \mathrm{~h}$ and analyzed by HPLC. Fresh buffer solution was replaced at each interval to maintain the sink condition of receptor compartment. The percentage of drug release was calculated and triplicates were conducted and the results averaged. ${ }^{21}$

\section{Release kinetic}

The drug release kinetics were investigated by fitting the drug release data into Korsmeyer pepaas/ and or Weibull kinetic as expressed by equation. ${ }^{22}$

Weibul kinetic: $F=1-\exp \left(-a t^{b}\right)--$ (Eq. 2)

Korsmeyer peppas: $\mathrm{M}_{\mathrm{t}} / \mathrm{M}_{\infty}=\mathrm{kt}^{\mathrm{n}---\mathrm{-n}^{---}}$(Eq. 3)

Ex vivo \& In vivo Studies

\section{Ethical Approval/Informed Consent}

This study was approved by the ethical review board of Gomal University, D. I. Khan, Pakistan under reference no. ERB/Gu/1923/2019. All the subjects (Human volunteers) were informed about the study and informed consent was obtained from parents and/or legal guardian of the participants for both study participation and publication of identifying information/images. The animals and human studies were performed in accordance with $\mathrm{NIH}$ and Helsinki guidelines respectively. The study is reported in accordance with ARRIVE guidelines. 


\section{Preparation of Skin}

Healthy male rabbit of family Leporidae and specie Oryctolagus cuniculus, weighing $1.5 \mathrm{~kg}$, were selected. Hair removing cream was applied on abdominal skin and hairs were removed. Full thickness skin was marked and then rabbit was euthanized and skin was removed with the help of a scissor. The subcutaneous fat present was carefully detached from the skin. The defatted skin was washed with $0.9 \%$ $\mathrm{w} / \mathrm{v} \mathrm{NaCl}$ solution; it was wrapped in an aluminum foil and stored in a freezer for further use. The thickness of skin was measured at three different points using a screw gauge and averaged. Prior to use all skin samples were thawed for $3 \mathrm{~h}$ at $25 \pm 2^{\circ} \mathrm{C} .{ }^{23}$

\section{Ex-vivo Drug Permeation}

Franz diffusion cell was used for the diffusion studies by using rabbit skin as a barrier between receiver and donor compartment. The skin was clamped in a way that its epidermis faces upward and dermis was in contact with receiving compartment. The receptor phase of the diffusion cell was filled with air bubblefree USP phosphate buffer saline $\mathrm{pH}$ 7.4. Matrix patch was placed on epidermis of the skin and experiment was ran for $24 \mathrm{hr}$. The temperature of the Franz cell was maintained at $37 \pm 1^{\circ} \mathrm{C}$. Two $\mathrm{ml}$ sample aliquot was withdrawn at specific time intervals of $0,0.5,1,1.5,2,4,6,8,12,16,20$ and $24 \mathrm{hr}$. Each time, fresh buffer was replaced to maintain the sink condition. The samples were analyzed on HPLC for quantification of extract (Drug) permeated. ${ }^{23}$

In vitro Leishmanicidal Activity

\section{Preparation of Lieshmanial Culture}

Leishmanial major strains of L. amazonensis in five test tubes with a maximum capacity of $8 \mathrm{ml}$ and temperature was maintained at $28^{\circ} \mathrm{C}$ having Warren's medium (Brain-heart infusion plus hemin and folic acid), $10 \%$ of inactivated fetal bovine serum, RMPI 1640 solution, penicillin 1001U/ml, streptomycin and gentamycin $100 \mu \mathrm{g} / \mathrm{ml}$ for the time period of 7 days up to the time promastigotes have been formed. This sample was transferred into a sterile culture flask for sub culturing, which have Schneider's insect medium (Sigma Aldrich, USA), pH 4.5, with $20 \%$ fetal bovine serum at $32^{\circ} \mathrm{C}$. Promastigotes were harvested after 6 days by centrifugation at 2000 RPM for 15 minutes, then pellets were made and washed with phosphate buffer solution having pH 7.2 two times and a haemocytometer (Improved Double Neubauer) was used to calculate the number of promastigotes which was $1 \times 10^{60} / \mathrm{ml}^{24}$

\section{Preparation of Stock Solutions}

One milligram of powder and crude extract of Nigella sativa seeds and formulation were dissolved in 50 $\mu \mathrm{l}$ of DMSO in separate test tubes and final volumes were made $1 \mathrm{ml}$ with same solvent. Then the reference drug Amphotericin B stock solution was made with the DMSO of $0.2 \mathrm{mg} / \mathrm{ml}$. All the stock solutions were kept in tightly closed vials and stored in refrigerator till further use. ${ }^{25}$ 
The assay was done by adopting 24 well micro titer plates. $100 \mu \mathrm{g}$ of Leishmania/culture of $1 \times 10^{60}$ promastigotes $/ \mathrm{ml}$ were transferred to all the wells, only the first well received $180 \mu \mathrm{g}$. Then $20 \mu \mathrm{g}$ of solubilized tested material was taken from the stock solution and added to the first well and mixed well with the micropipette. After the first well mixing sample aliquots of $100 \mu \mathrm{g}$ was taken from it and shifted to the second well and mixed, from second well shifted to the third well and from third to the fourth well and so on. So the first well received $100 \mu \mathrm{g} / \mathrm{ml}$ of the crude extract of drug while the last well contained only $0.78 \mu \mathrm{g} / \mathrm{ml}$, for positive and negative control last two wells were used, one contained DMSO and the other have standard drug of Amphotericin B, in both quantities were $0.2 \mathrm{mg} / \mathrm{ml}$, the final volume of DMSO was below $0.5 \%$ to avoid its dangerous effect on growth of parasites. Then all the well along with the controls were incubated for 72 hours. After incubation a drop of culture was placed on the slide and the number of promastigotes were counted with a haemocytometer and light microscope. The results were compared with the controls. IC ${ }^{50}$ was calculated and the extract results were compared with the standard drug and percentage inhibition was calculated. ${ }^{25}$

\section{In vivo Anti-Lieshmanial Studies in Human Being}

For in vivo study, 30 insensitive patients were recruited in this study to evaluate the effectiveness of the $N$. sativa loaded formulation. Prior to the formulation application, a dermatologist/physician examined the person to confirm the disease (Leishmaniasis). Volunteers were not informed about the contents of formulation. On the first day, patch test (Burchard test) was performed on the forearms of each volunteer to determine any possible reactions/sensitivity to the formulation. The volunteers were instructed to apply the formulation for 3 weeks. Every individual was instructed to come every week for the skin measurements/lesion observation during study period. All the subjects were informed about the study and informed consent was signed by their families, while the study was approved by institutional ethical committee.

\section{STATISTICAL ANALYSIS}

All the results were analyzed by T-test (SPSS, Version 20, IBM software) for determination of mean and standard deviation and level of significance at $P<0.05$.

\section{Results And Discussion}

\section{Phytochemical Screening}

Results of present research comprise a scientific justification and suggested the use of Nigella sativa seeds. Qualitative phytochemical evaluation of seeds (Nigella sativa) showed the presence of alkaloids, glycosides, terpenoides, tannins, saponins, flavonoids while reducing sugars were not present (Table II). Many studies reported the presence of alkaloidal, saponins, flavonoids, terpenoids, tannins which have anti-Lieshmanial, ant parasitic activity, tannins are astringent in nature and resistant to enzymatic attack so good for healing process but reducing sugars are absent in Nigella sativa seeds. ${ }^{25-28}$ 
Table II. Phytochemical Parameters of Extract of Nigella sativa Seeds

\begin{tabular}{|ll|}
\hline \multicolumn{2}{|l|}{ Screening Result } \\
\hline Phytochemicals & Nigella sativa extract \\
\hline Alkaloids & $+\mathrm{ve}$ \\
\hline Carbohydrates & $-\mathrm{ve}$ \\
\hline Terpenoids & $+\mathrm{ve}$ \\
Flavonoids & $+\mathrm{ve}$ \\
Tannins & $+\mathrm{ve}$ \\
\hline Saponins & $+\mathrm{ve}$ \\
\hline
\end{tabular}

\section{+; Present, - Absent}

\section{Physical Evaluation of Patches}

The important factor in stability and activity of transdermal patches depends upon its physicochemical characteristics which are smoothness, clarity, thickness, weight variation, folding endurance, moisture uptake and percent moisture content of the patch. In recent years there has been great advancement in the use of transdermal patches for carrying drugs as a vehicle to the body as the bioavailability of the drugs is high in this dosage form. Smoothness, clarity and brittleness of the patch are very important for its elegant look and for complete contact with the skin. Weight variation test was done to observe that patch weight should not be greater than or lower than a significant level because too heavy patch will detach from the skin after some time. ${ }^{28}$ Similar study was done by Namdeo et al, they developed transdermal patches of Quetiapine fumerate for treating psychosis by use of EC and HPMC as polymers, DMSO as penetration enhancer and PEG-400 as plasticizer. ${ }^{29}$

\section{Smoothness, Brittleness and Clarity Analysis}

The prepared transdermal patches of Nigella sativa seeds extract were smooth, clear and uniform moreover there were no cracks or roughness and brittleness. The results are given in the Table III.

Table III. Physical characteristics of Nigella sativa transdermal patches 


\begin{tabular}{|lllll|}
\hline Formulation Codes & Smoothness & Clarity & Brittleness & Overall Appearance \\
\hline N 1 & + & + & $\times$ & Satisfied \\
N2 & + & + & $\times$ & Satisfied \\
N 3 & + & + & $\times$ & Satisfied \\
N4 & + & + & $\times$ & Satisfied \\
N5 & + & + & $\times$ & Satisfied \\
\hline
\end{tabular}

\section{Thickness of Patch}

The thickness of transdermal patches of Nigella sativa seeds extract was determined by use of micrometer screw gauge, at different points and the thickness was ranged between 0.201 to $0.250 \mathrm{~mm}$. The results are shown in Table IV.

\section{Folding Endurance}

From each batch one patch was selected and it was folded at three different places and all the patches of Nigella sativa seeds extract have folding capacity of more than 70 times. Results are shown in Table IV.

Table IV. Physicochemical Tests of Nigella sativa Transdermal Patches

\begin{tabular}{|llllll|}
\hline $\begin{array}{l}\text { Formulation } \\
\text { Codes }\end{array}$ & $\begin{array}{l}\text { Thickness } \\
(\mathrm{mm}) \pm \text { SD }\end{array}$ & $\begin{array}{l}\text { Weight } \\
\text { uniformity }(\mathrm{mg}) \\
\mathbf{\pm S D}\end{array}$ & $\begin{array}{l}\text { \%Moisture } \\
\text { uptake } \pm \text { SD }\end{array}$ & $\begin{array}{l}\text { \%Moisture } \\
\text { content } \pm \text { SD }\end{array}$ & $\begin{array}{l}\text { Folding } \\
\text { endurance } \pm \\
\text { SD }\end{array}$ \\
\hline NS1 & $0.242 \pm 0.22$ & $232.00 \pm 1.02$ & $22.00 \pm 1.03$ & $3.66 \pm 0.500$ & $8.13 \pm 1.23$ \\
\hline NS2 & $0.203 \pm 0.10$ & $216.00 \pm 1.21$ & $16.00 \pm 1.11$ & $5.000 \pm 1.00$ & $7.33 \pm 1.52$ \\
\hline NS3 & $0.234 \pm 0.12$ & $212.00 \pm 1.10$ & $12.00 \pm 1.11$ & $3.333 \pm 0.51$ & $7.33 \pm 0.52$ \\
\hline NS4 & $0.250 \pm 0.32$ & $222.00 \pm 1.00$ & $3.33 \pm 0.57$ & $81.00 \pm 1.01$ & $9.33 \pm 0.67$ \\
\hline NS5 & $0.218 \pm 0.21$ & $219.00 \pm 1.20$ & $29.00 \pm 1.00$ & $6.00 \pm 1.21$ & $8.66 \pm 1.52$ \\
\hline
\end{tabular}

\section{Weight Variation Results}

All the patches were weighed from five batches by using digital weighing balance and the results were triplicated and weight variation test was satisfactory. No patch showed significant change in weight from that of average of all patches. Results are tabulated in Table IV.

\section{Percentage Moisture Uptake}

The percentage of moisture uptake by the transdermal patches at room temperature and relative humidity of $84 \%$ for 24 hours of time duration are shown in Table IV. As the formulation contained three different polymers which were HPMC, PVP K30 and EC, so the moisture uptake depends on these polymers, due to more quantity of EC than HPMC and PVP high concentration of moisture uptake was observed in it. The 
percentage moisture uptake ranged between 11 to $30 \%$. Those patches which have more quantity of HPMC revealed more moisture uptake due to its hydrophilic nature. The results showed that incorporation of enhancer resulted in increased percent moisture uptake. As a whole the capability of patches to take moisture followed the following sequence; HPMC > HPMC/PVP > PVP > PVP/PVA $>$ PVA. Results tabulated in Table IV.

\section{Fourier Transforms Infrared Spectroscopy}

Figures $1 \mathrm{a}, 1 \mathrm{~b}$ and $1 \mathrm{c}$ exhibit FTIR spectra of pure Nigella sativa seeds extract, transdermal patch of extract and powder of seed respectively at mid infrared region of $4000-400 \mathrm{~cm}^{-1}$. FTIR spectra of all three samples appeared fairly same, however clear examination revealed significant differences in number of peaks. At region $3000-2500 \mathrm{~cm}^{-1}$ pure extract have no peak, transdermal patch have two broad peaks and powder have two sharp peaks. These peaks were attributed to $\mathrm{O}-\mathrm{H}$ stretching vibration. The peaks at region $1700 \mathrm{~cm}^{-1}$ showed $\mathrm{C}=0$ stretching vibrations. Peaks at $1200-1000 \mathrm{~cm}^{-1}$ attributed to $\mathrm{C}-\mathrm{N}$ stretching, peaks at $1600-1400 \mathrm{~cm}^{-1}$ showed $\mathrm{C}=\mathrm{N}$ vibrations. It is concluded that $\mathrm{O}-\mathrm{H}$ stretching show alcoholic group, $\mathrm{C}=\mathrm{N}$ reveals imine group and $\mathrm{C}=\mathrm{O}$ stretching confirms different groups like aldehydes, ketones, carboxylic acids, ester, amide, anhydride and acid chloride. All the principal peaks were also present in polymer formulation with little changes in frequencies which showed that there was no interaction between polymers and the drug. Results are shown in Fig. 1. The broader peaks at $3200 \mathrm{~cm}^{-1}$ in Fig. 3 (crushed powder from seeds) shows the presence of alcohols and phenols in the seed powder. While the intensity of same peak was much higher in case of crude extract and extract loaded transdermal patches possibly because of strong $\mathrm{O}-\mathrm{H}$ stretching of hydroxyl group from methanol or water. Multiple peaks from 600 to 1600 in Fig. 4.3 confirmed the presence of various active phytoconstituents ranging from alkenes (1600) to aromatics (1400) to alkyl halides $(600-700)$. Strong carbonyl stretching at 1650 further confirms the presence of wide variety of organic compounds such as 1550 to 1650 resulted from $C=N$ which shows an imine group. In case of crushed seeds powder the $C=0$ stretching confirms many different groups like aldehydes, ketones, carboxylic acids, ester, amide, anhydride and acid chloride. ${ }^{30}$

\section{In vitro Release Study}

In vitro release study was performed by Franz diffusion cell using three transdermal patches to confirm the type of release. Significant differences were observed in the release of Nigella sativa patches containing hydroxyl-propyl-methyl-cellulose (HPMC), Polyvinyl-pyrolidone (PVP) and Ethyl cellulose (EC). During this process the patches were swelled forming a gel layer on the exposed patch surfaces. The loosely bound polymer molecules in these patches were readily eroded, allowing the easy release of nigella sativa extract. It was found that the crude extract released from the patches varied with respect to the proportion of polymers. After 24 hours the release was found to be $55.3 \%, 68.5 \%$ and $87.0 \%$ in the formulation NS1, NS3, NS5 respectively. Amongst all formulations, formulation NS5 showed significantly good release pattern as compared to others. Results are given in Fig. 2. Little difference was observed in the release of Nigella sativa seed extract patches containing different proportions of hydroxyl-propyl- 
methyl-cellulose (HPMC), ethyl cellulose (EC) and polyvinyl-pyrolidone (PVP) due to the binding capacity of these polymers. It was revealed that ethyl cellulose has the highest binding force with the drug Nigella sativa seed extract. Amongst all formulations the formulation NS4 showed the good release pattern as compared to others because of high concentration of ethyl cellulose. Same studies and findings were revealed by Mutalik and Udupa (2004) and the drugs released from the patches were calculated by korsmeyer pappas kinetics which varied with respect to the proportion of polymers. All formulations shown good release pattern as compared to others. ${ }^{31}$

\section{Evaluation of Drug Release Mechanism by Various Kinetic Models}

Various kinetic models can be employed to investigate drug release mechanism of the formulations using in vitro release data, but here only Korsmyers Peppas model was used. The in vitro release data was fitted to this model to find that either the release follows fickian or non fickian diffusion. The mechanism by which the drug is released from the patch can be determined by the value of $n$. If the value of $n$ equals 0.5 then the diffusion is fickian diffusion but if it lies between 0.5 and 1 then called anomalous diffusion and if the value of $\mathrm{n}$ is equal to 1 than it shows Case-II transport and if it's greater than 1 then Super case-II transport mechanism. Hence, to confirm the exact mechanism of drug permeation from these patches, the data were fitted to the Korsmeyer-Peppas model. In the present study, the coefficient of determination ( $R 2=0.992$ to 0.995 ) was found to be much closer to 1 and the release exponent ' $n$ ' value varied between 0.426 to 0.771 , which explained that drug released from the patch occurred by Non-fickian type of diffusion. Overall results of kinetic modeling suggest that diffusion is dominant mechanism for drug release following Non-Fickian type of diffusion.

Release data were analyzed by Korsmeyer-Peppas model.

$M_{t} / M_{\infty}=k t^{n}$

Where $\mathrm{Mt} / \mathrm{Ma}$ is the fraction of drug released at time ' $\mathrm{t}$ ' and ' $\mathrm{k}$ ' is the rate constant and a function of the physical properties of the drug delivery system and ' $n$ ' is the release exponent The values for the release exponent ' $n$ ' are listed in Table V. The slope of Korsmeyer-Peppas plot were found to be $0.5688,0.5292$, 0.5580 in the formulation NS1, NS3 and NS5 respectively which confirms that the drug release is mediated solely by fickian diffusion mechanism. As the drug release depends on hydrophobicity of the polymers and it decreases with increase in hydrophobic increase. Hence, to confirm the exact mechanism of drug permeation from these patches, the data was fitted to the Korsmeyer-Peppas model and the results for $\mathrm{n}$ meant that the mechanism for drug release follows Anomalous non fickian diffusion. Fickian diffusion is derived from ficks law of diffusion which explains that the polymer relaxation time $\left(t_{r}\right)$ is much higher than the solvent diffusion time $\left(t_{d}\right)$ but when this polymer relaxation time $\left(t_{r}\right)$ is almost equal to solvent diffusion time $\left(t_{d}\right)$ than its called anomalous non fickian diffusion to simplify the complex release process from the transdermal patches there is need of mathematical modeling which give details 
about release mechanisms of a specific material system, similar study was done by Mutalik and Udupa (2004) and they confirmed that the drug release is mediated solely by diffusion mechanism. ${ }^{31}$

Table V. Korsmeyer-Peppas values for drug release from NS transdermal patches

\begin{tabular}{|c|c|c|c|c|}
\hline Formulation & $\mathrm{K} \pm \mathrm{SD}$ & $r^{2}$ & $\mathbf{N}$ & \\
\hline NS1 & $\begin{array}{l}0.0190 \pm \\
0.04259\end{array}$ & $\begin{array}{l}0.9492 \pm \\
0.0600\end{array}$ & $\begin{array}{l}0.5688 \pm \\
0.0231\end{array}$ & $\begin{array}{l}\text { Anomalous non fickian } \\
\text { diffusion }\end{array}$ \\
\hline NS3 & $\begin{array}{l}0.0130 \pm \\
0.03525\end{array}$ & $\begin{array}{l}0.8863 \pm \\
0.0279\end{array}$ & $\begin{array}{l}0.5292 \pm \\
0.0011\end{array}$ & $\begin{array}{l}\text { Anomalous non fickian } \\
\text { diffusion }\end{array}$ \\
\hline NS5 & $\begin{array}{l}0.0190 \pm \\
0.04448\end{array}$ & $\begin{array}{l}0.9441 \pm \\
0.0632\end{array}$ & $\begin{array}{l}0.5580 \pm \\
0.0001\end{array}$ & $\begin{array}{l}\text { Anomalous non fickian } \\
\text { diffusion }\end{array}$ \\
\hline
\end{tabular}

\section{Ex vivo Drug Permeation}

As samples were taken at regular time intervals and evaluated by HPLC. In this work, it was observed that as the concentration of polymers varied in the formulations (NS1, NS3, and NS5). The mean accumulative amounts of percent crude extract permeated also showed variation in drug permeation. Hence formulation NS5 has very good permeation pattern up to $80 \%$ across the skin, also the percent drug permeated was increased with time (Fig. 3). The percent drug permeated was $40 \%$ at six hours, $60 \%$ at 12 hours and $80 \%$ at 24 hours, which shows that the drug permeated well with the passage of time due to DMSO. Similar study was done by Nicoli et al., (2006), they made oxybutynin bio-adhesive films by use of PVA ( $30 \%$ solution), Plastoid $E 35 \mathrm{H} \circledast 27$, Sorbitol $70 \%$ and evaluated its in-vitro permeation on rabbit skin, with a good permeation. ${ }^{32}$

In vitro Anti-Leishmanial Assay

In vitro assay of Leishmanial parasite was done for crude extract of Nigella sativa seed, grinded powder of Nigella sativa seed and transdermal patch of Nigella sativa seed extract. The IC ${ }^{50}$ values of standard drug amphotericin-B, crude powder, crude extract and extract loaded transdermal patch were found to be $20.0 \mathrm{ug} / \mathrm{ml}, 18.50 \mathrm{ug} / \mathrm{ml}, 45.20 \mathrm{ug} / \mathrm{ml}$ and $38.92 \mathrm{ug} / \mathrm{ml}$ respectively. The percentage inhibition of amphotericin-B was supposed to be $100 \pm 0.02 \%$ and then percentage inhibition of crude powder, crude extract and formulation were calculated from it, which were found to be $92.5 \pm 0.21 \%, 226.0 \pm 0.43 \%$ and $194.6 \pm 0.21 \%$ respectively. Assay result is given in Table VI. There was significant increase in in vitro antileishmanial activity of the Nigella sativa seeds crude extract and its loaded transdermal patch as compared to standard drug amphotericin-B. Similar research study of anti-Leishmanial activity was done by Hossein et al in 2014 who concluded that Nigella sativa extracts exhibited an effective Leishmanicidal activity against $L$. tropica on in-vitro model, using a clinical setting further works are required to evaluate the exact effect of these extracts on Leishmania species. ${ }^{35}$

Table VI. In-vitro anti-Leishmanial Assay results 


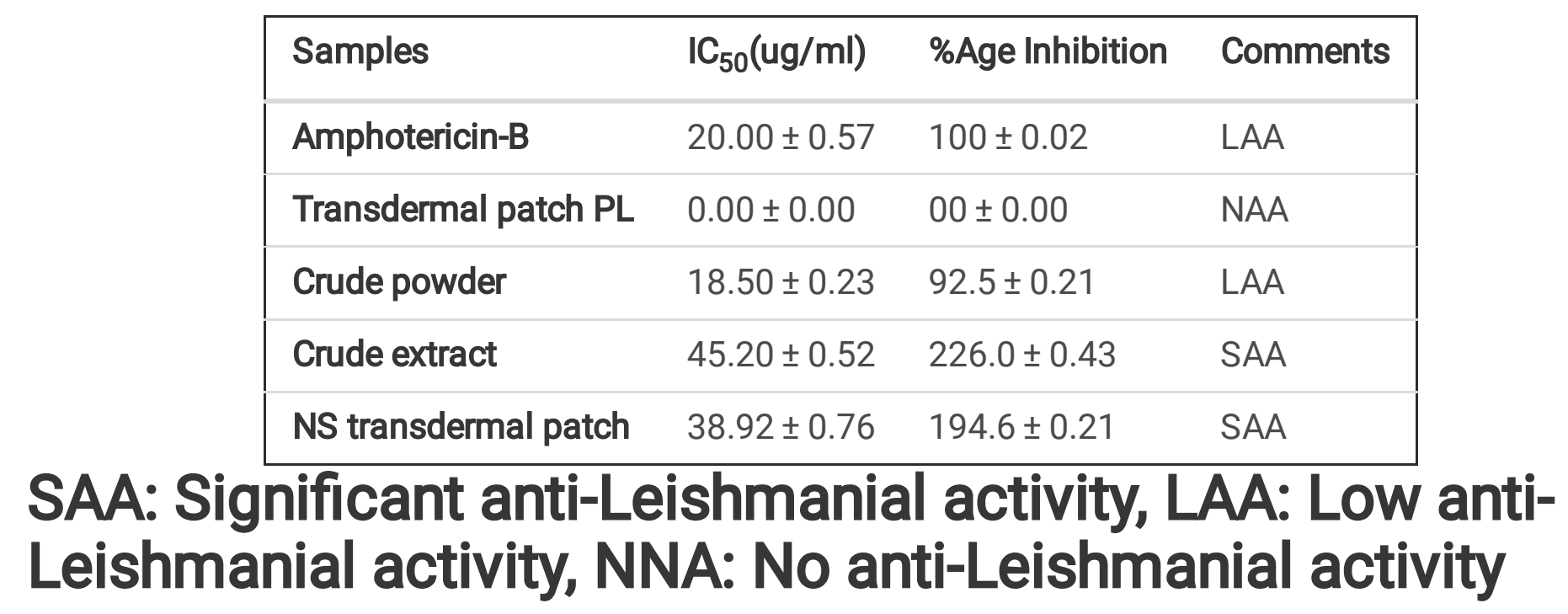

In vivo Anti-Lieshmanial Studies in Human Volunteer

In this study the effectiveness of the NS extract containing transdermal patch was evaluated in human volunteer. Patients $(n=30)$ were included in the study according to inclusions criteria for antileishmanial treatment. The mean number of lesion per patient was 1.2 and mean lesion size of the patients was 25.3 $\mathrm{mm}$. Every patient was treated for 2 to 3 weeks. The cure rate in the patients included in the study was $73 \%$. Measurements and calculations for all lesions and indurations were recorded separately and presented in Table VII. Figures 4 show the pre-treatment and post-treatment photographs of the patients. NS formulations showed good results during therapy period with percentage cure rate of $73 \%$ while failure rate was $27 \%$ which may be due to non-compliance to treatment, involvement of other species of leishmania or secondary infections to which therapy may not be effective. During the study, L. major did not produce visceral infection in the patients so they seemed to be suitable model/volunteers for the present study. The fact that there was no other treatment applied by the patients indicates that the healing, to any extent, was due to topical treatment alone using NS formulation. These finding are in agreement to the results of the study conducted by Parvaneh et a/ who formulated topical ointment containing crude extracts of Peganum harmala, however they used animal model rather than human volunteers. ${ }^{36}$

Table VII. In-vivo study on NS extract containing transdermal patches in patients with cutaneous Leishmaniasis.

\begin{tabular}{|l|l|}
\hline No of patients & 30 \\
\hline Mean no of lesions per patients & 1.2 \\
\hline Mean lesion size SD $(\mathrm{mm})$ & $25.3 \pm 0.1$ \\
\hline No. of cured patients & 22 \\
\hline No. of patients for whom therapy failed & 08 \\
\hline Cure rate in percentage & $73 \%$ \\
\hline
\end{tabular}




\section{Conclusion}

The finding of this work revealed that the problems of drugs parenterally used for Lieshmania/ treatment can be managed by applying extract of Nigella sativa seeds in the form of transdermal patch. Nigella sativa seeds extract contained thymoquinone which have potentiating effect for anti-parasitic activity. As an extension of this work pharmacokinetic studies, in-vivo studies on higher animals and controlled clinical studies on human beings can be carried out in future.

\section{Declarations}

\section{Consent for publication}

Not applicable

\section{Availability of data and materials}

It can be obtained from the corresponding author on request.

\section{Competing interest}

All the authors declare that they have no competing interest

\section{Funding}

There was no financial support for this research study.

\section{Author's contributions}

BAK designed and supervised the study plan. YA performed all the experiments. THK helped in writing of the manuscript. MQ edited the manuscript and did the formal analysis. SMA and MKK helped in the formulation development and statistical analysis. All authors have read and approved the manuscript.

\section{Acknowledgment}

We are thankful to Dr. Nauman Rahim Khan (Lecturer at Faculty of Pharmacy, Gomal University, D. I. Khan, Pakistan) for helping us in FTIR analysis. We are also grateful to Dr. Muhammad Anwar Bhittani (Children Specialist, DHQ, Hospital, Tank, Pakistan) for helping us in in vivo studies.

\section{References}

1. Ahmad, A., Husain, A., Mujeeb, M., Siddiqui, N.A., Damanhouri, Z.A., Bhandari, A. (2014). Physicochemical and phytochemical standardization with HPTLC fingerprinting of Nigella sativa $L$. 
Pakistan Journal of Pharmaceutical Sciences, 27(5), 1175-82.

2. Aggarwal, G., Dhawan, S. (2009). Development, fabrication and evaluation of transdermal drug delivery a review. Journal of Pharmaceutical Science, 5 (7), 2076-2089.

3. msf.org/only-option-cutaneous-leishmaniasis-treatment-pakistan

4. Bafghi, A.F., Mirzaei, F.M. (2015). Antileishmanial activity of Nigella sativa extract against Leishmania major. An in vitro study. Journal of Chemical and Pharmaceutical Research, 7(7):12391244.

5. Bafghi, A.F., Vahidi, A.R., Anvari, M.H., Barzegar, K., Ghafourzadeh, M. (2011). The in-vivo antileishmanial activity of alcoholic extract from Nigella sativa seeds. African Journal of Microbiology Research, 5(12), 1504-1510.

6. Baraa, N.A., Shaker, R.M., Kahtan, A.A., Khudair K K (2012). Effect of Flavonoids Extracted from Black Cumin (Nigella sativa) and Vitamin E in Ameliorating Hepatic Damage Induced by Sodium Nitrate in adult male rats. Proceeding of the Eleventh Veterinary Scientific Conference, 172 -181.

7. Blum, J., Desjeux, P., Schwartz, E., Beck, B., Hatz, C. (2004). Treatment of cutaneous Leishmaniasis among travellers. Journal of Antimicrobial Chemotherapy, 53(2), 158-66.

8. Barkat, A.K., Naveed, A., Tariq, M., Mughal, Q., Shahiq-uz-Zaman. (2010). Formulation and pharmaceutical evaluation of a W/O emulsion of Hippophae rhamniodes fruit extract. Journal of Pharmacy Research, 3(6),1342-1344.

9. Chehl, N., Chipitsyna, G., Gong, Q., Yeo, CJ., Arafat, HA. (2009). Anti-inflammatory effects of the Nigella sativa seed extract, thymoquinone, in pancreatic cancer cells. The Official Journal of the International Hepato Pancreato Biliary Association, 11(5), 373-381.

10. Dhaval, PP., Chitral, MS., Gaurav, NM., Santnu, LP., Tarun, JP., Pritesh, CM., Amar, KR., Pritesh, KP., Rishabh, SM. (2009). Development and Evaluation of Ethyl Cellulose-Based Transdermal Films of Furosemide for Improved In Vitro Skin Permeation. American Association of Pharmaceutical Scientists, 10(2), 437-442.

11. Debjit, B., Chiranjib, Margret, C., Jayakar, B., Sampath, K.P. (2010). Recent advances in transdermal drug delivery system. International Journal of Pharmaceutical Technology Research, 2 (1), 68- 77

12. Forouzanfar, F., Bazzaz, B.S.F., Hosseinzadeh, H. (2014). Black cumin (Nigella sativa) and its constituent (thymoquinone): a review on antimicrobial effects. The Iranian Journal of Basic Medical Sciences, 17(12), 929-938

13. Feroz, S., Uddin, G. (2016). Phytochemical Analysis, Antimicrobial and Antioxidant Study of Nigella sativa L. International Journal of Pharmacy and Chemistry, 2(2), 39-43

14. Guerin, P.J., Lliaro, P.O., Sundar, S., Boelaert, M., Croft, S.L., Desjeux, P., Wasanna, M., Bryceason, A.D.M. (2002). Visceral Leishmaniasis: current status of control, diagnosis, and treatment, and a proposed research and development agenda. The Lancet Infectious Disease, 2, 494-501.

15. Asma, M., Hicham, M., Kaouthar, B., Benboubetra, M., Hemama, B. (2012). Polyphenolic profile and antioxidant activities of Nigella sativa seed extracts in-vitro and in-vivo. International Journal of Biological, 16(4), 109-117. 
16. Gholamnezhada, Z., Rafatpanahb, H., Sadeghnia, H.R., Boskabadya, M.H. (2015). Immunomodulatory and cytotoxic effects of Nigella sativa and thymoquinone on rat splenocyte. Food and Chemical Toxicology, 86, 72-80.

17. Hossein, M., Fariba, S., Monireh, S.R., Razieh, T., Ebrahim, S.D., Sareh, J., Iraj, S. (2014). Evaluation of antileishmanial activity and cytotoxicity of the extracts of Berberis vulgaris and Nigella sativa against Leishmania tropica . Journal of Vector Borne Diseases, 51, 294-299

18. Iman, I.S., Nadia, A.S., Ebtsam, M.A. (2010). Formulation and stability study of chlorpheniramine maleate transdermal patch. Asian Journal of Pharmaceutics, 70(4), 455-60.

19. Jude, E.O., Ahsana, D.F., Mohammed, I.C. (2013). Cellular antioxidative, cytotoxic, and antileishmanial activities of Homalium letestui. Avicenna Journal of Phytomedicine, 3(1), 35-44.

20. Jarallah, H.M. (2003). Effect of some plant extract and antibiotics with histopathological study on Leishmania major M.Sc. Thesis. Edu. Coll. Univ. Basrah. 116.

21. Jarallah, H.M. (2005). Effects of Trigonella Foenum-Graecum seeds extracts on promastigote of Leishmania major. Basrah Journalof Agricultural Sciences, 18(2), 9-16.

22. Kamil, Z.H., Nergiz, C., otles, S. (2013). Spectacular black seeds (Nigella sativa): medical importance review chemical composition of Nigella sativa L Food Chemistry, 48, 259-26.

23. Kaye, P., Scott, P. (2011). Leishmaniasis: complexity at the host-pathogen interface. Nature Kusum, V.D., Saisivam, S., Maria, G.R., Deepti, P.U. (2003). Design and Evaluation of Matrix Diffusion Controlled Transdermal Patches of Verapamil Hydrochloride. Drug Development and Industrial Pharmacy, 29(5), 495-503.

24. Reviews Microbiology, 9(8), 604-615.

25. Landa, P., Marsik, P., Havlik, J., Kloucek, P., Vanek, T., Kokoska, L. (2009). Evaluation of antimicrobial and anti-inflammatory activities of seed extracts from six Nigella sativa Journal of Medicinal Food, 12(2), 408-415.

26. Micheal, E.A. (2014). Pharmaceutics. The Science of Dosage Form Design. 2, 504,505,509.

27. Mohammed, H.H., Arias, C.R. 2016. Protective efficacy of Nigella sativa seeds and oil against columnaris disease in fishes. Journal of Fish Diseases, 39, 693-703.

28. Namdeo A, Garud N, Garud A (2012). Development and Evaluation of Transdermal Patches of Quetiapine fumerate for the treatment of psychosis. International Journal of Drug Delivery, 4, 470476.

29. Nicoli, S., Penna, E., Padula, C., Colombo, P., Santi, P. (2006). New transdermal bio-adhesive film containing oxybutynin: In vitro permeation across rabbit ear skin. International Journal of Pharmaceutics, 325, 2-7.

30. Nurrulhidayah, A.F., Chemana, Y.B., Al-Kahtani, H.A., Rohman, A. (2011). Application of FTIR spectroscopy coupled with chemometrics for authentication of Nigella sativa seed oil. Spectroscopy, 25(5), 243-250. 
31. , Udupa. (2004). Glibenclamide transdermal patches: physicochemical, pharmacodynamic, and pharmacokinetic evaluations. Journal of Pharmaceutical Sciences, 93(6), 1577-94

32. Ramdas, S. (2012). Cruel disease, cruel medicine: Self-treatment of cutaneous Leishmaniasis with harmful chemical substances in Suriname. Social Science \& Medicine, 75(6), 1097-1105.

33. Rajan, R., Ding, S.C., Sheba, R.N.D. (2013). Development of Transdermal Ondansetron Hydrochloride for the Treatment of Chemotherapy-Induced Nausea and Vomiting. Tropical Journal of Pharmaceutical Research, 12 (3), 279-285

34. Sundar, S., More, D.K., Singh, M.K., Singh, V.P., Sharma, S., Makharia, A., Kumar, P.C., Murray, H.W. (2000). Failure of pentavalent antimony in visceral Leishmaniasis in India: report from the center of the Indian epidemic. Infectious Diseases Society of America, 31(4), 1104-1107.

35. Shah, S.S., Joshi, R., Prabhakar, P. (2010). Formulation and evaluation of transdermal patches of papaverine hydrochloride. Asian Journal of Pharmaceutics, 4(1), 79-86.

36. Trease , GE., Evans ,WC. (2002). 15th Ed. London: Saunders Publishers, pp. 42-44. 221-229, 246$249,304-306,331-332,391-393$.

\section{Figures}


A
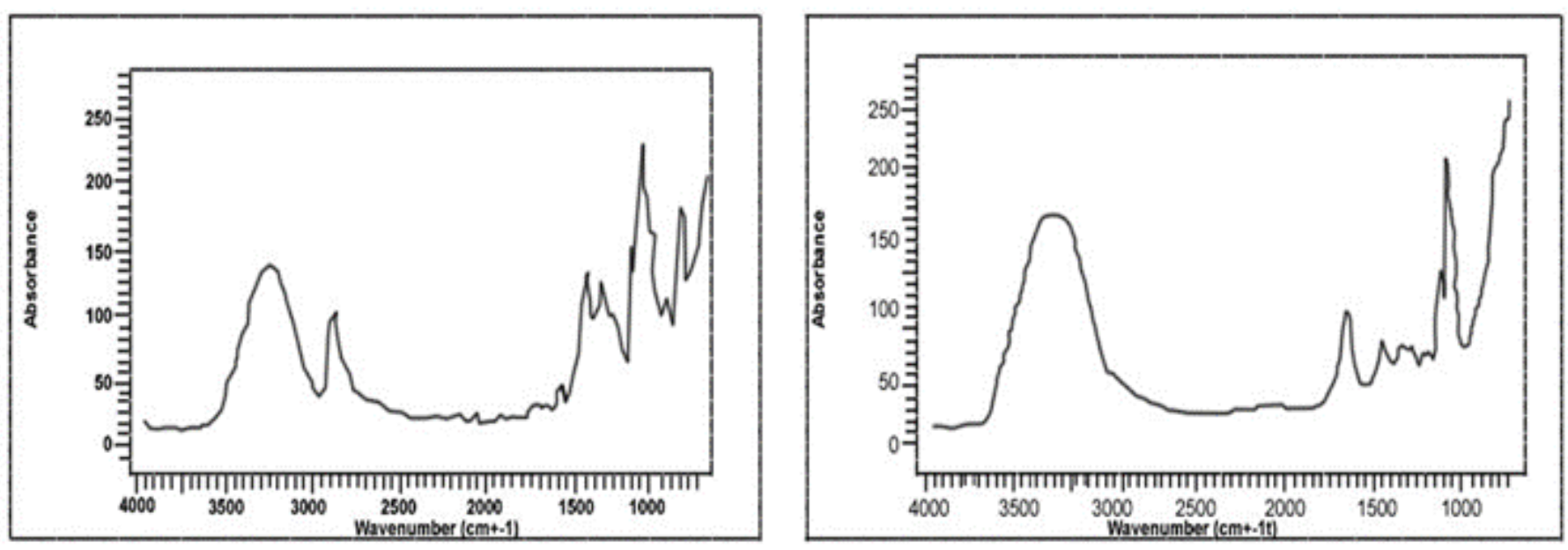

C

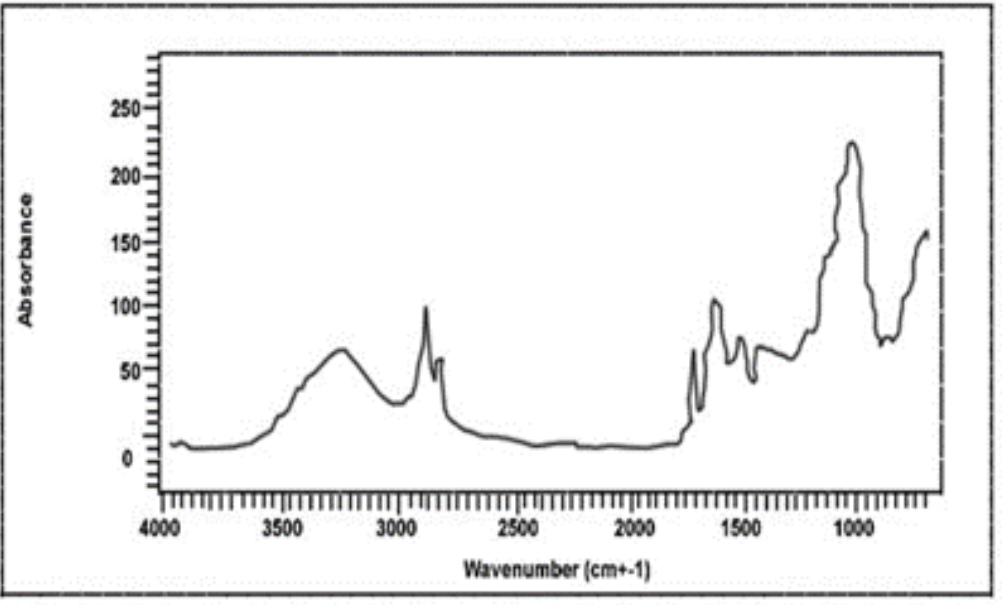

Figure 1

FTIR of Nigella sativa seeds extract 1b) FTIR of transdermal patch of Nigella sativa seeds extract 1c) FTIR of crushed powder of NS seeds 


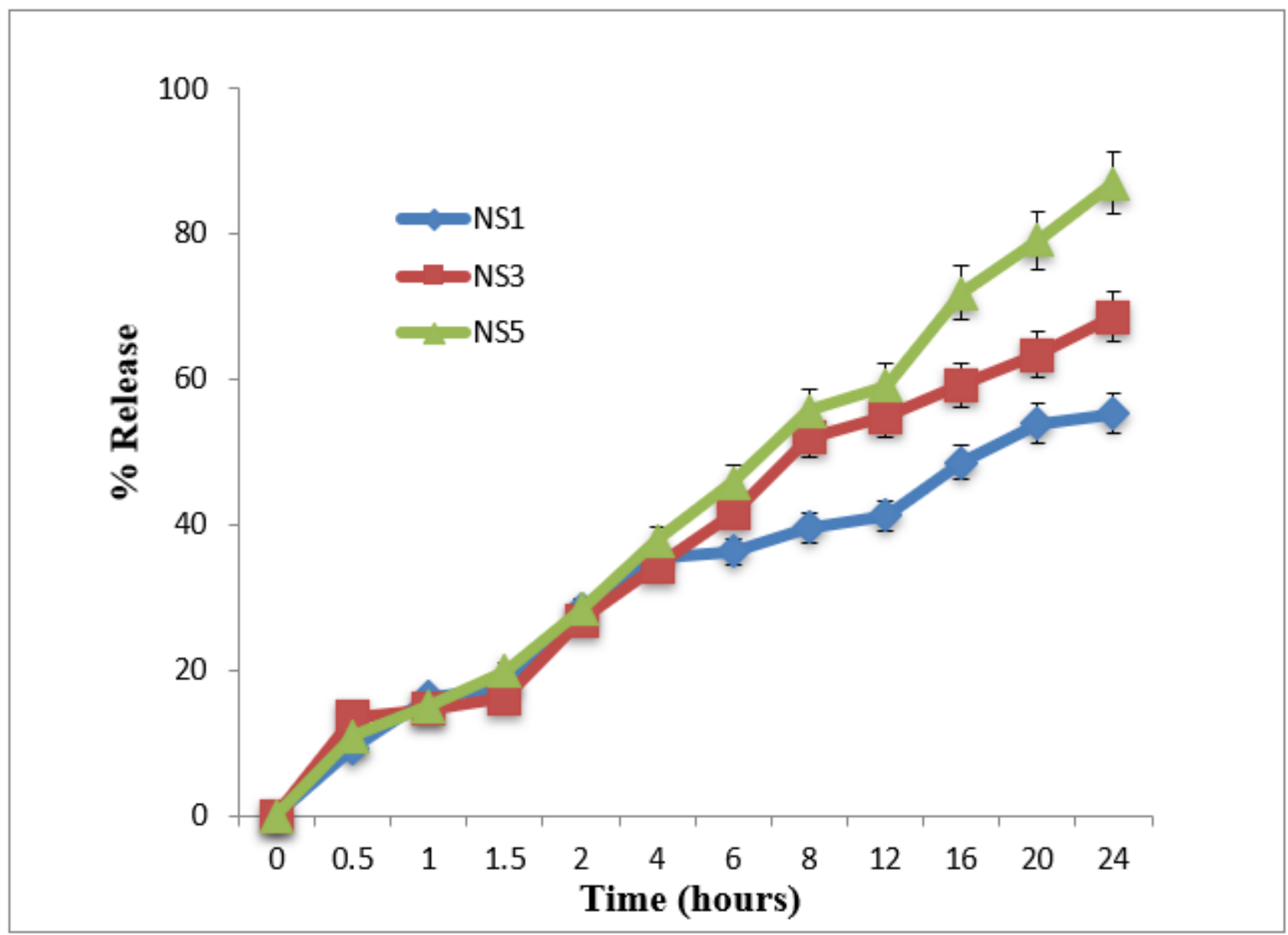

Figure 2

Percentage release of Nigella sativa seeds extract from three formulations of transdermal patches at different time intervals. 


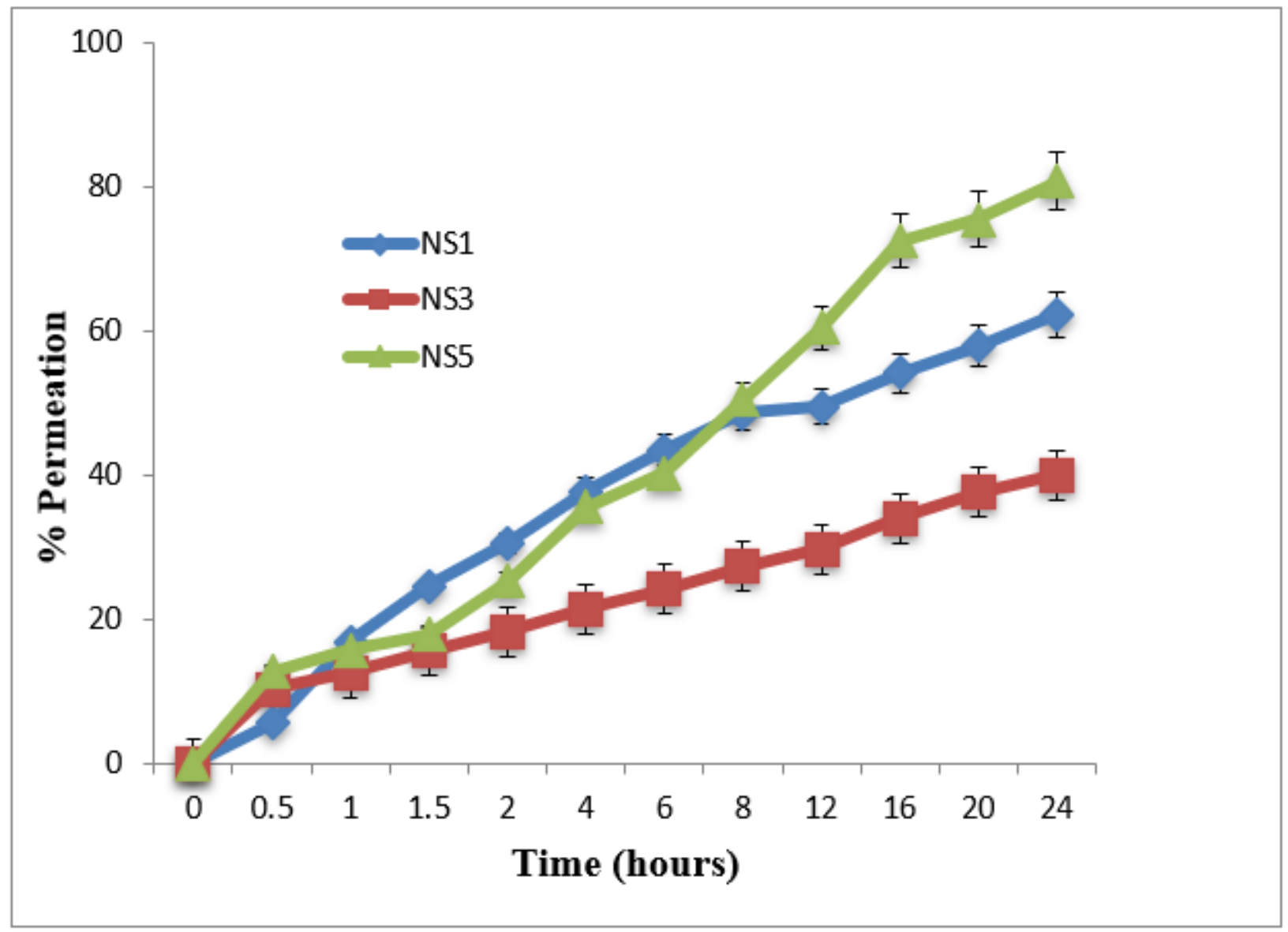

Figure 3

Percent permeation of Nigella sativa seeds extract from three formulations of transdermal patches at different time intervals 


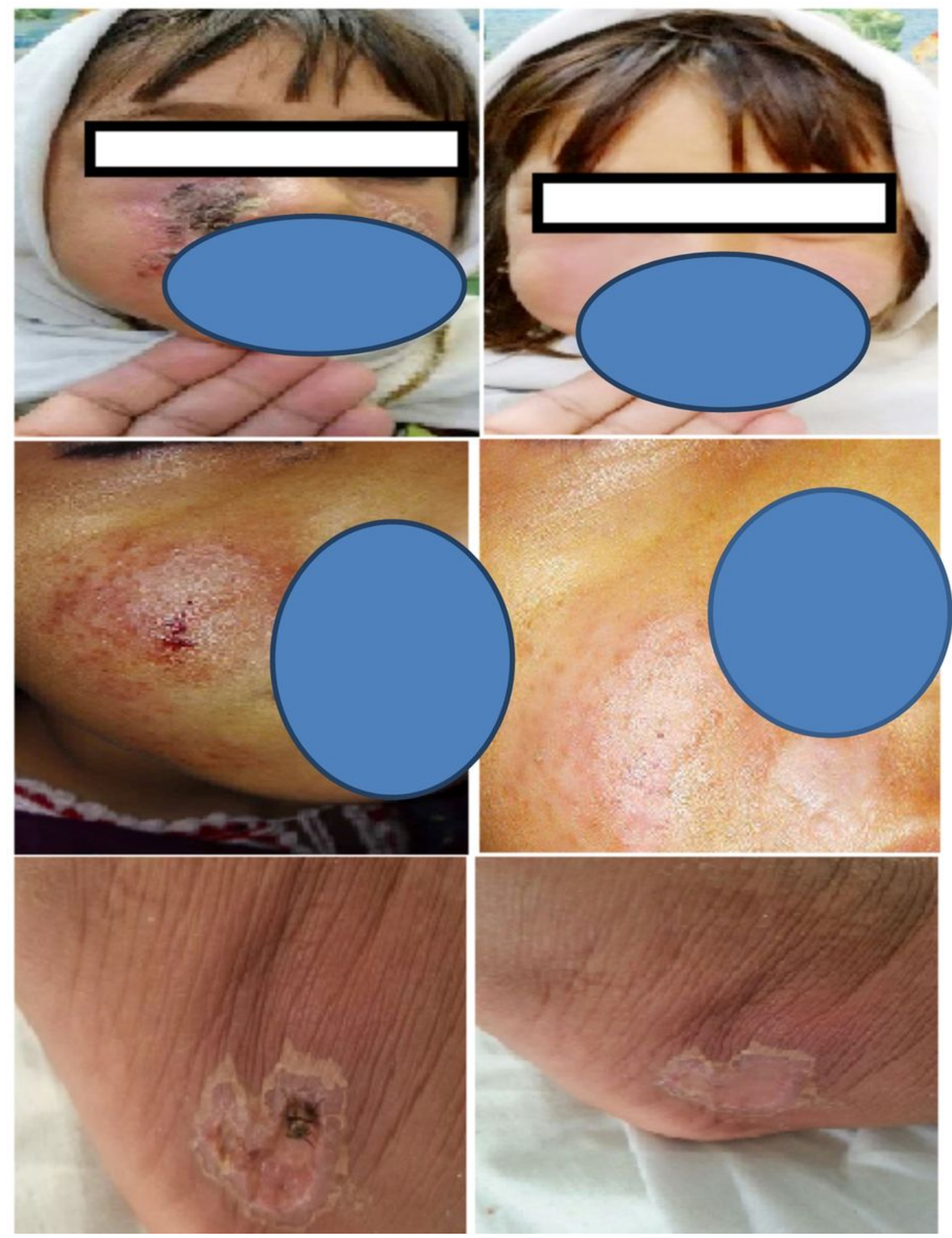

Figure 4

Pre-treatment and Post treatments photographs of Patients treated with NS formulation for 2-3 weeks 